\title{
Fifty years of Koedoe: CurRent status and future DIRECTIONS
}

\author{
LLEWELLYN C. FOXCROFT \\ South African National Parks \\ Conservation Services \\ South Africa
}

Tel.: +27137354125

Fax: +27 137354055

e-mail: koedoe@sanparks.org

Postal Address: South African National Parks, Conservation Services, Private Bag X402, Skukuza, 1350, South Africa

Koedoe has reached a milestone in its history in producing this, the 50th volume. Published annually since 1958 by the then National Parks Board and biannually since 1989, more than 845 articles have been published in the journal. There has also been one monograph, The reptile fauna of the Kruger National Park (1966), and there have been two supplementary issues, Proceedings of a symposium on the status of nature conservation in Southern Africa (1977) and Proceedings of a symposium on the Kalahari ecosystem (1984). The Scientific bibliography on the national parks of South Africa (1994) has also been published.

Koedoe has covered a variety of fields, producing baseline information on which management plans and monitoring programmes rest today. Some of the older papers are still cited regularly. These include Assessing veld condition in the Kruger National Park using key grass species by Trollope, Potgieter and Zambatis (1989) and Landscapes of the Kruger National Park by Gertenbach (1983). Moreover, articles in Koedoe have stimulated research and added immeasurably to our knowledge of South Africa's biodiversity and appropriate management.

In addition, articles in Koedoe have included a number of checklists and reports of species new to science. Scanning the output of the journal over the decades provides clear evidence of how, from early and tentative scientific ventures in the national parks of South Africa, knowledge of species has grown. In later years, there was a change of emphasis in science that found its place in Koedoe as more articles on patterns of vegetation and habitats appeared and as articles on species identification and collection gave way to ecosystems research. Koedoe has spread its reach over the years, too, and early concentration on scientific research in the Kruger, Kalahari Gemsbok and Addo Elephant national parks has adapted to include all South Africa's national parks as well as conservation areas under other structures and even those protected elsewhere in Southern Africa.

A number of people have contributed to Koedoe's success and it would be remiss of me not to extend our sincere gratitude to them. Firstly, SANParks would like to thank Mrs Kobie Rautenbach for her great contribution: Mrs Rautenbach was associated with Koedoe for 20 years, 10 as assistant editor and 10 as editor with full responsibility for Koedoe. I would also like to express our thanks to the members of the previous editorial board for their great support and input into the journal: Dr CK Brain, Prof. MN Bruton, Dr SK Eltringham, Prof. MB Fenton, Prof. BL Penzhorn, Dr B Stuckenberg, Dr JG Teer and Prof. GK Theron. At the beginning of 2007, Mrs Rautenbach handed over the task of editor to me and thus the large challenge of following in her footsteps.

While a 50th-volume milestone provides the opportunity to reflect on the past, it also gives the opportunity to plan and reorganise for the future. In order to be successful, a scholarly journal should firmly establish itself in a specific niche. In doing so, it needs to distinguish itself from the large number of other journals on related subjects and to gain a reputation for

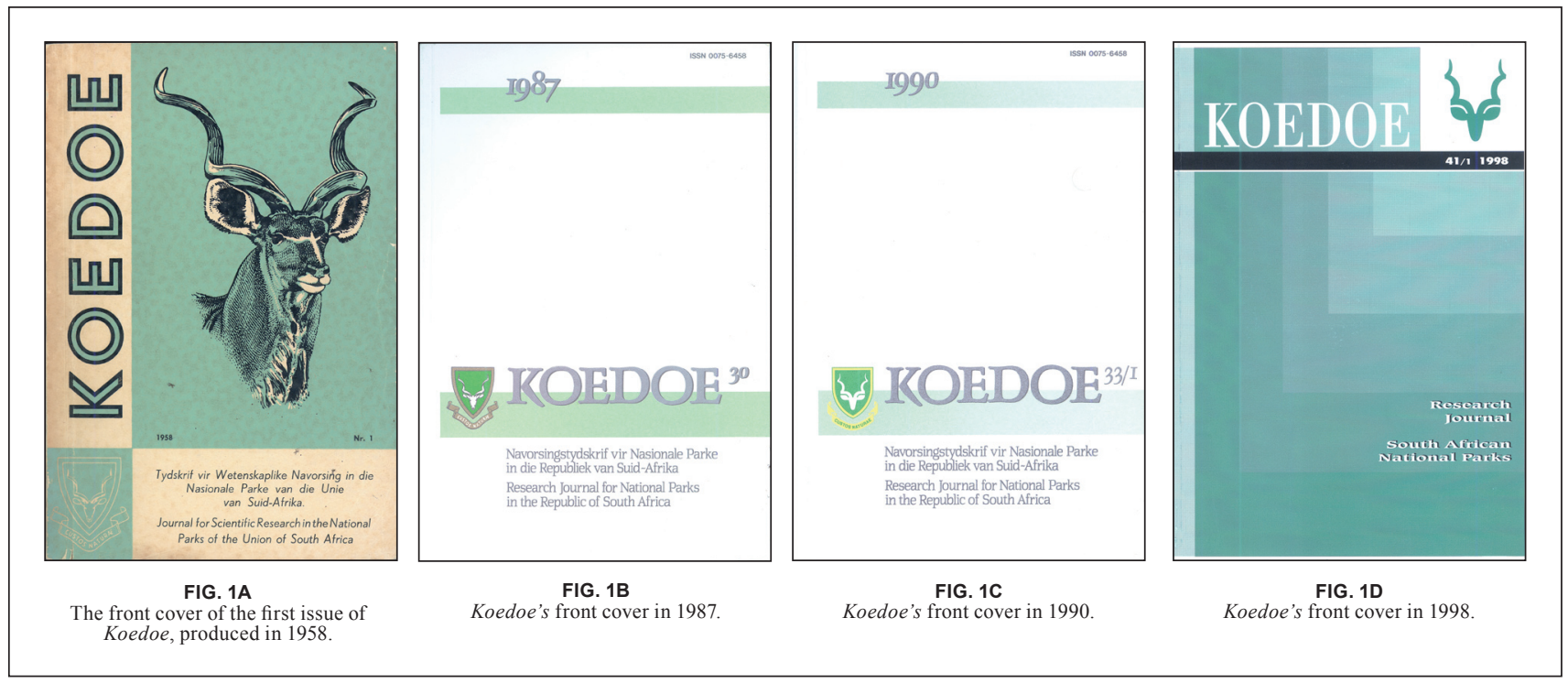

FIGURE 1

Koedoe covers from 1958 to 1998 . 
publishing papers only of high scientific quality. Developing a strong niche area and raising the profile of a journal are a slow process; achieving this will be my highest priority for the next few years.

During the year since I became editor, I approached a number of renowned scientists to join the editorial board; I would like to thank the following people for taking on the role for the period 2007 to 2010: Prof. William Bond, University of Cape Town; Prof. Jane Carruthers, University of South Africa; Prof. Charles Griffiths, University of Cape Town; Prof. Conrad Matthee, Stellenbosch University; Prof. David Meltzer, University of Pretoria; Prof. Gretel van Rooyen, University of Pretoria; Dr Bob Scholes, Council for Scientific and Industrial Research, and Prof. Di Scott, University of KwaZulu-Natal.

We have added a new subtitle, African Protected Area Conservation and Science, to Koedoe to capture the new aims and aspirations for the journal. Our goal is to become soughtafter, attracting quality papers concerned with all aspects of science, management and policy for all types of protected areas across the African continent. This mission brings with it an extremely exciting opportunity and potential for future manuscript submissions from experts in the field as well as a wider readership.

As you will have noticed, Koedoe: African Protected Area Conservation and Science has a different format (see Figures 1A to $\mathrm{D}$ for the changes in Koedoe's format over time). The new look and format (see Figure 2) aim to revitalise the image of the journal, positioning it strategically to make use of modern publishing technologies. After careful consideration of the options, we have decided to use Open Access as the publication medium for the journal. Following an inaugural meeting of editors of scholarly journals in South Africa convened by the Academy of Science of South Africa (ASSAf), Open Access was clearly shown to be beneficial in widening access to South Africa's research journals. Instead of having a print distribution of merely a few hundred copies, the number of people who can view and download papers from Koedoe through the use of the World Wide Web is virtually limitless. Downloading articles is free, and distribution to people by email using PDF files is convenient and easy. This means that the potential readership of articles increases substantially. In addition, articles can be published as soon as they have gone through the peer-review and proof stages, thus hastening the process of availability. These are only some of the advantages of Open Access; a comprehensive report (Academy of Science of South Africa, 2006) is available from ASSAf (visit www. assaf.org). Because I know that there will still be readers and authors who prefer the journal in hard copy, we are pleased to let you know that our publishers (OpenJournals Publishing, a division of African Online Scientific Information Systems) will have a print-on-demand (subscriber) option as well.

Thank you to those who have supported Koedoe for half a century, whether as authors, reviewers, editorial-board members or in any of the many other ways. I very much look forward to continuing the relationship with all of you and to growing the journal for the benefit of conservation.

Llewellyn Foxcroft, Editor.

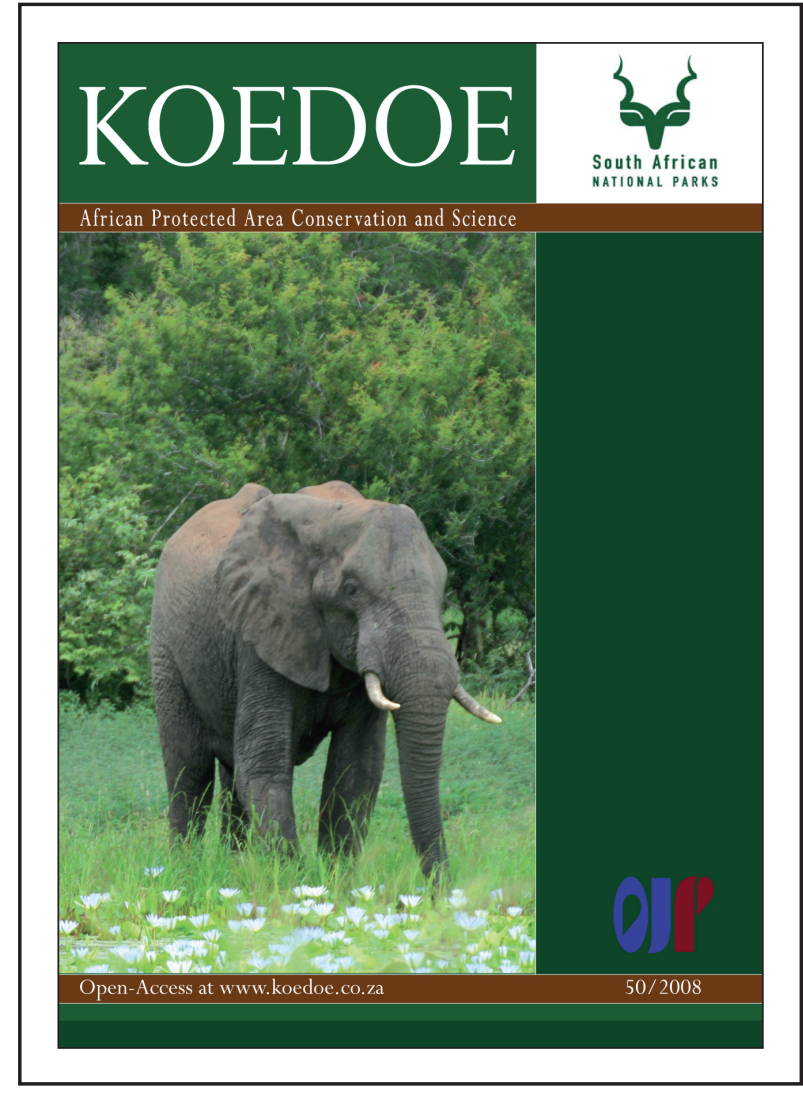

FIGURE 2

A new front-cover style for Koedoe, launched in conjunction with Koedoe's 50th volume anniversary.

\section{ACKNOWLEDGEMENTS}

I thank SANParks for its continued support of Koedoe and specifically Dr Peter Novellie, Dr Stefanie Freitag-Ronaldson and Mr Danie Pienaar for useful discussions and input over the last year. Prof. Jane Carruthers provided helpful comments on this editorial.

\section{REFERENCES}

Academy of Science of South Africa. 2006. Report on a strategic approach to research publishing in South Africa. Pretoria: Academy of Science of South Africa (www.assaf.org.za).

Bryden, H.B. \& De Vos, V. 1994. Scientific bibliography on the national parks of South Africa. Koedoe Supplement, 1-133.

Gertenbach, W.P.D. 1983. Landscapes of the Kruger National Park. Koedoe, 26:9-122.

Pienaar, U. de V. 1966. The reptile fauna of the Kruger National Park. Koedoe Monograph, 1:1-223.

Trollope, W.S.W., Potgieter, A.L.F. \& Zambatis, N. 1989. Assessing veld condition in the Kruger National Park using key grass species. Koedoe, 32(1):67-94.

Various authors. 1977. Proceedings of a symposium on the status of nature conservation in Southern Africa. Koedoe Supplement, 1-260.

Various authors. 1984. Proceedings of a symposium on the Kalahari ecosystem. Koedoe Supplement, 1-333. 